\title{
Prediction of Dengue Fever Outbreak Based on Case Household Locations in Southern Taiwan
}

\author{
Pui-Jen Tsai \\ Center for General Education, Aletheia University, Taiwan \\ Email:puijentsai@gmail.com
}

How to cite this paper: Tsai, P.-J. (2020) Prediction of Dengue Fever Outbreak Based on Case Household Locations in Southern Taiwan. Open Journal of Preventive Medicine, 10, 175-193.

https://doi.org/10.4236/ojpm.2020.107013

Received: June 8, 2020

Accepted: July 24, 2020

Published: July 27, 2020

Copyright $\odot 2020$ by author(s) and Scientific Research Publishing Inc. This work is licensed under the Creative Commons Attribution International License (CC BY 4.0).

http://creativecommons.org/licenses/by/4.0/

\section{(c) (i) Open Access}

\begin{abstract}
Dengue fever is a serious vector-borne infectious viral disease found worldwide. Dengue fever forecasting is in demand in the front line of epidemic prevention and control work. The goal of this study was to evaluate the feasibility of using only notified case home locations to predict new cases and village locations. We took the Tainan City dengue fever outbreak in 2015 as the research subject and divided it into 5 periods according to epidemic temporal change. In each period, the predicted variable was the location of the reported cases in the previous week, the previous 2 weeks, and the previous 3 weeks. In addition, we used 21 preset distances with a radius of 0 to $2000 \mathrm{~m}$ at intervals of $100 \mathrm{~m}$ to predict the villages where new cases would appear. Accounting for 4 predictors of a confusion matrix at each preset distance, these predictors were used in calculations using the Matthews correlation coefficient (MCC) as the basis for model evaluation. In the lag phase, the optimal predictor was within $1700 \mathrm{~m}$ in the 3 -week forecast. In the exponential phase, the optimal predictor was within $300 \mathrm{~m}$ in the 1-week forecast. In the stationary phase, the optimal predictor was within $100 \mathrm{~m}$ in the 3-week forecast and within 200 $\mathrm{m}$ in the 2 -week forecast. In the early decline phase, the optimal predictor was $0 \mathrm{~m}$ in the 1-week forecast. In the late decline phase, the optimal predictor was within $200 \mathrm{~m}$ in the 2-week forecast. According to MCC calculations and comparisons among the 5 studied periods, the best MCC score was in the exponential phase, a stage of rapid increase of new cases. The results of this study suggest that the epidemic forecasting model based on the location of notified cases has a high reference value for epidemic control and prevention.
\end{abstract}

\section{Keywords}

Spatial Analysis, Matthews Correlation Coefficient, Dengue Outbreak, Forecast 


\section{Introduction}

Of all the currently existing virus-borne diseases, dengue fever (DF) has the greatest clinical impact, with approximately 96 million infections per year and nearly 4 million life-threatening cases [1] [2]. Dengue is transmitted by Aedes mosquitoes, primarily by the highly urban-adapted vector Aedesaegypti and a secondary vector $A$. albopictus [3]. Taiwan is geographically located in a region that spans both tropical and subtropical climates $\left(22-25^{\circ} \mathrm{N}\right.$ and $\left.120-122^{\circ} \mathrm{E}\right)$. The latitude of $23.5^{\circ} \mathrm{N}$ divides the island into two climatic zones: 1) a tropical monsoon climate in the South and 2) a subtropical monsoon climate in the North. The latitude, topography, ocean currents, and prevailing East Asian summer monsoon over Taiwan contribute to the island's high temperature, humidity, and rainfall, as well as tropical cyclones during summer [4]. Although both $A$. aegypti and $A$. albopictus are prevalent in Taiwan, they have different distributions [5] [6]. A. albopictus is extensively distributed at elevations of less than $1500 \mathrm{~m}$ throughout the island, whereas $A$. aegypti appears only in the south, below the Tropic of Cancer $\left(\right.$ i.e., $23.5^{\circ} \mathrm{N}$ ) and the Penghu Islet [6]. DF is a travel-related disease in Taiwan because travelers can carry the dengue virus from endemic areas to the island. After this virus is transported to the island, it is passed to Aedes mosquitoes, which can cause an outbreak of indigenous DF [7] [8] [9] [10]. Historical epidemics of DF in Taiwan have been documented in 1902, 1915, and 1922 in the Penghu Islet; in 1924, 1927, and 1931 in southern Taiwan; and in 1942 to 1943 across Taiwan [11]. Since 1998, the Taiwan Centers for Disease Control (CDC) have recorded 9 outbreaks, with more than 1000 cases of DF or dengue hemorrhagic fever/dengue shock syndrome in 2002, 2006, $2007,2009,2010,2011,2012,2014$, and 2015, respectively [12]. With a few exceptions, these outbreaks occurred in the south of Taiwan, where $A$. aegypti is prevalent and coexists with $A$. albopictus.

In Taiwan, for more efficient control and prevention of dengue transmission, it is necessary to establish a simple and accessible model for predicting dengue outbreaks. Several models have been developed. One focuses on monitoring large dengue epidemic areas, such as a city district [13] or a whole city and county [14] [15] [16], neglecting smaller administrative areas such as urban villages. Targeting these smaller areas is usually considered to be a priority for the practical prevention and control of dengue epidemics. Another predicts urban villages of new dengue onset but requires many predictors, such as the daily number of reported DF cases, population density in each village, and daily weather variables of precipitation and temperature, to be measured in advance [17]. DF forecasting is generally considered to be too complicated for the use of standard methods of prediction. Therefore, the aim of this study was to evaluate the feasibility of dengue risk forecasting in urban villages by using only the household location of reported cases to develop a simpler and more efficient strategy for the control and prevention of dengue transmission. 


\section{Methods}

\subsection{Study Area and Data Set}

Tainan City, the study area, is $2191.65 \mathrm{~km}^{2}$ in area and contains 649 urban villages. It is located in southern Taiwan, south of the Tropic of Cancer, and is a tropical climate zone (as shown in Figure 1). The area of the urban villages ranges from $0.05 \mathrm{~km}^{2}$ to $82.9 \mathrm{~km}^{2}$, with the average area being $3.38 \mathrm{~km}^{2}$. Because of rules regarding personal privacy, patients' real household locations cannot be revealed in any official public information. Therefore, this study used the center of the basic statistical unit of area as a substitute. A basic statistical area was established using criteria such as uniformity of population density, doorplate number, and socioeconomic activity, which is the smallest unit of administrative data available for collection in Taiwan. We also considered characteristics of the

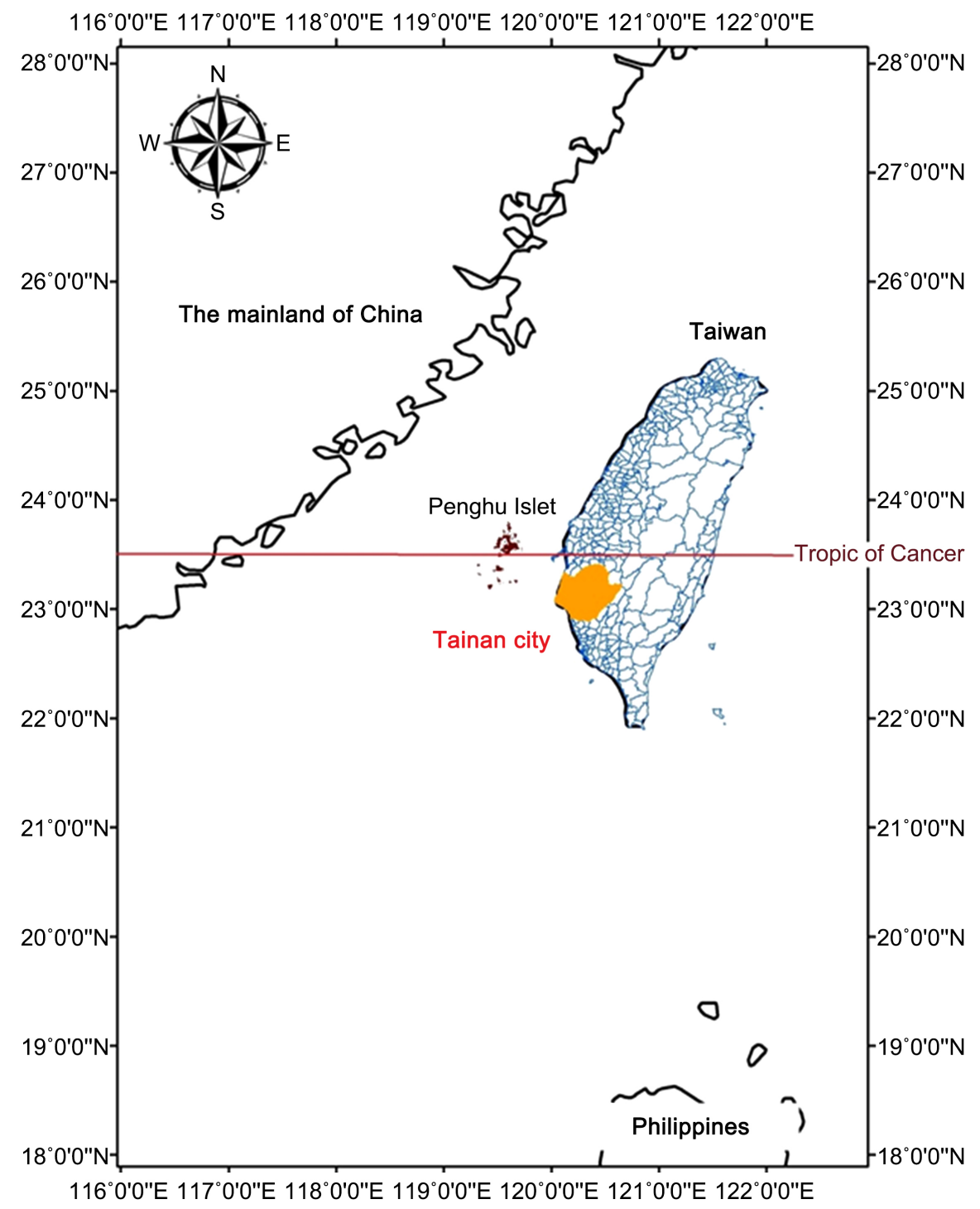

Figure 1. Geographical location of Taiwan and the study area. The study area is shown in yellow. 
original data, such as the spatial distribution of street corners, roads, and rivers. The center of the basic statistical area was defined by coordinates at its household location with cases of dengue infection. There are 12,774 units of the basic statistical area in all of Tainan City, with an average of 19.7 units (range: 1 - 69) in each urban village [18]. The data set of daily confirmed dengue cases during 2015, which included onset day, coordinates, and whether the case was imported or indigenous, was obtained from the Taiwan CDC. A total of 21,924 cases were identified [19] [20]. According to the change in incidence density during all of 2015 , the pattern of dengue incidence growth was classified into 5 phases: the lag phase (period of slow increase in number of new cases), the exponential phase (period of rapid increase in number of new cases), the stationary phase (period of stagnation in number of new cases), the early decline phase (early period of decline in number of new cases), and the late decline phase (new cases declined back to the level of the initial period). These phases are shown in Figure 2. Each studied phase consisted of 4 weeks. The research design was as follows: In the lag phase, the criterion variable was the case spatial distribution in the 29th week, and the predictor variables were the number of cases in the 26th, 27th, and 28th weeks. In the exponential phase, the criterion variable was the case spatial distribution in the 33rd week, and the predictor variables were the number of cases in the 30th, 31st, and 32nd weeks. In the stationary phase, the criterion variable was case spatial distribution in the 37th week, and the predictor variables were the number of cases in the 34th, 35th, and 36th weeks. In the early decline phase, the criterion variable was the case spatial distribution in the 41 st week, and the predictor variables were the number of cases in the 38th, 39th, and 40th weeks. Finally, in the late decline phase, the criterion variable was the case spatial distribution in the 45th week, and the predictor variables were the number of cases in the 42nd, 43rd, and 44th weeks, respectively.

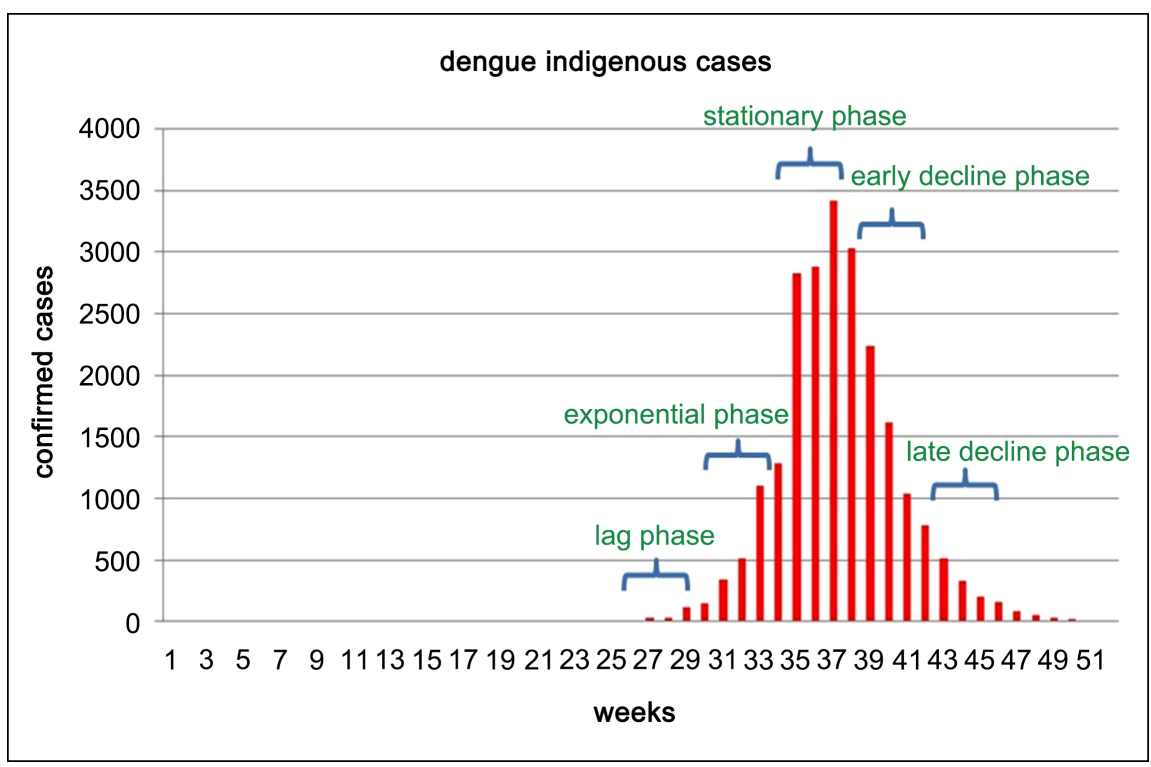

Figure 2. Weekly number of dengue onset cases in the study area (Tainan City) in 2015. 


\subsection{Spatial Analysis and Evaluation Metric for Dengue Forecast Models}

In this study, we used coordinates in the center of the basic statistical area instead of in the actual locations of confirmed dengue cases. As shown in Figure 3, which displays how the predictor variable was designated from one studied week, every case's coordinates are predicted according to 21 conditions, with their radius spanning from 0 to $2000 \mathrm{~m}$ in intervals of $100 \mathrm{~m}$. The areas created using the predicted radius were used to geographically intersect with urban villages, with urban villages overlapped for positive prediction; otherwise, they were negative. Cases confirmed in the week of the criterion variable were considered positive cases; otherwise, they were considered negative cases. According to a comparison of our predicted urban villages and the locations of actual cases, the outcomes of the classification were used to construct a $2 \times 2$ table, as shown in Table 1. The table includes true-positive, false-positive, false-negative, and true-negative cases. The 4 classifications are as follows: Actual positive cases that were correctly predicted within positive urban villages, called true positives (TP); actual negative cases that were falsely predicted within positive urban villages, called false positives (FP); actual positive cases that were falsely predicted within negative urban villages, called false negatives (FN); and actual negative cases that were correctly predicted within negative urban villages, called true negatives (TN).

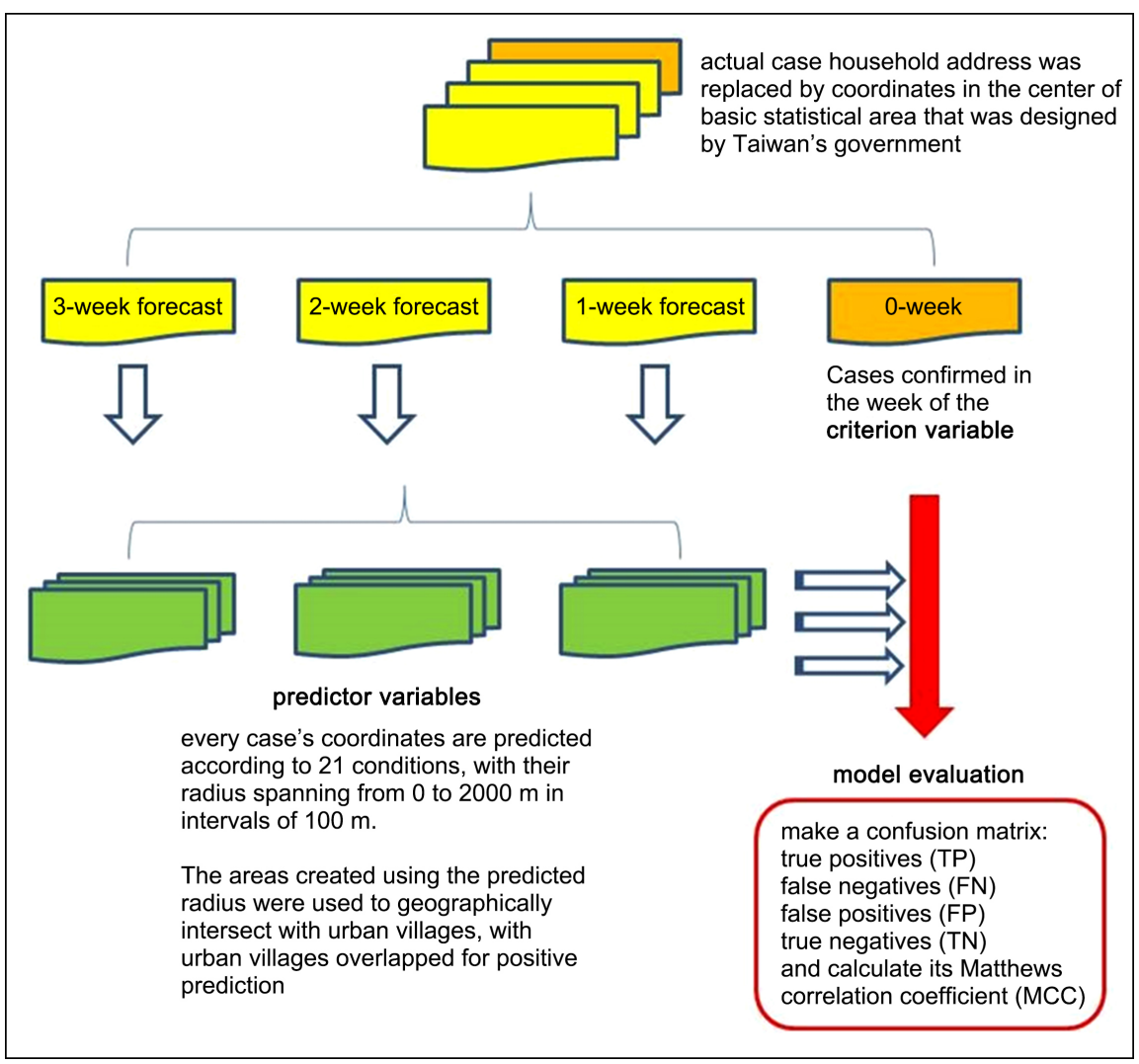

Figure 3. Flowchart of data processing. 
Table 1. The standard confusion matrix.

\begin{tabular}{cll}
\hline & Predicted Positive & Predicted Negative \\
\hline Actual Positive & True Positives TP & False Negatives FN \\
Actual Negative & False Positives FP & True Negatives TN \\
\hline
\end{tabular}

The Matthews correlation coefficient (MCC) is the coefficient of correlation between actual and predicted binary classifications [21] [22]. The MCC is also commonly used as a balanced measure, even if the classes are of very different sizes [23]. It is the optimal metric for the study of various incidences during a dengue outbreak period. In terms of the entries of the confusion matrix, MCC reads as follows:

$$
\mathrm{MCC}=\frac{\mathrm{TP} \times \mathrm{TN}-\mathrm{FP} \times \mathrm{FN}}{\sqrt{(\mathrm{TP}+\mathrm{FP}) \times(\mathrm{TP}+\mathrm{FN}) \times(\mathrm{TN}+\mathrm{FP}) \times(\mathrm{TN}+\mathrm{FP})}}
$$

It ranges between -1 and +1 . The value +1 represents a perfect prediction; 0 represents no better than random prediction; and -1 indicates total disagreement between the prediction and observation.

Spatial analysis and mapping were performed using ArcMap 10.4.

\section{Results}

While studying the cases of DF in 37 administrative districts of Tainan City in 2015, we observed that the places with a high incidence density had a clustering distribution (as shown in Figure 4), which indicated that the incidence was highly correlated with population density. In this study, it was substantively classified into 5 phases: the lag phase, the exponential phase, the stationary phase, the early decline phase, and the late decline phase. The predictor variable in each phase was divided into 63 individual conditions. According to weekly dengue case positions, predictions were 21 conditions based on radius distances ranging from 0 to $2000 \mathrm{~m}$ in intervals of $100 \mathrm{~m}$, with $63(21 \times 3)$ predictions spanning 3 weeks. Moreover, the radius distance at $0 \mathrm{~m}$ indicates that the predicted place is at the same location where cases of dengue occurred in the village of the predictor.

In the lag phase, the number of dengue cases predicted using the predictor variables in the 26th week (the 3-week forecast) totaled 9, the number of cases in the 27th week (the 2-week forecast) totaled 31, and the number of cases in the 28 th week (the 1-week forecast) totaled 28 . The number of cases of dengue infection in the 29th week totaled 116, and those were assigned as a criterion variable. The MCC results are displayed in Figure 5(a). The maximum value of MCC in the 26th week was 0.447 , and the predictor was within the radius of $1700 \mathrm{~m}$. A contingency table of the confusion matrix was true-positive cases: 34 , false-positive cases: 64 , false-negative cases: 13 , true-negative cases: 538 , as shown in Figure 5(b). The maximum value of MCC in the 27th week was 0.404, 


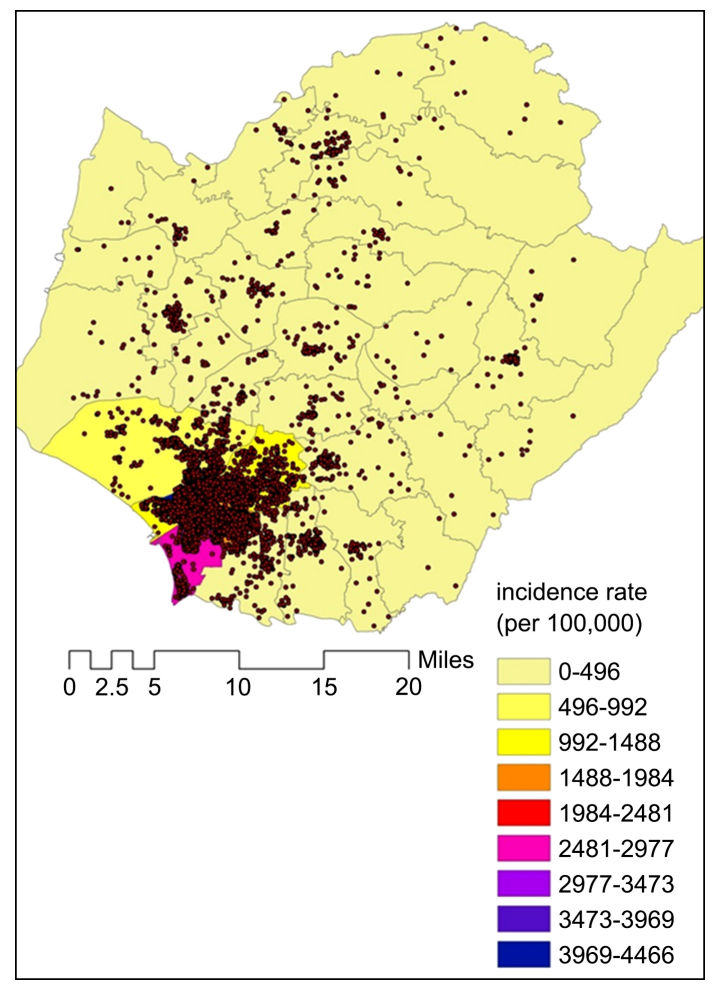

Figure 4. Geographical distribution of confirmed dengue cases and incidence density of the study area in 2015.

and the predictor was within the radius of $900 \mathrm{~m}$. A contingency table of the confusion matrix was true-positive cases: 36 , false-positive cases: 90 , false-negative cases: 11, true-negative cases: 512, as shown in Figure 5(c). The maximum value of MCC in the 28th week was 0.407 , and the predictor was within the radius of $1100 \mathrm{~m}$. A contingency table of the confusion matrix was true-positive cases: 33 , false-positive cases: 73, false-negative cases: 14, true-negative cases: 529, as shown in Figure 5(d). The top six outcomes of MCC values among $21 \times 3$ predictions included predictors that are at radii of $1400,1500,1600,1700,1800$, and $1900 \mathrm{~m}$ during the 26th week.

In the exponential phase, the number of dengue cases predicted using the predictor variables in the 30th week (the 3-week forecast) totaled 414 . That in the 31 st week (the 2-week forecast) totaled 336, and that in the 32nd week (the 1 -week forecast) totaled 512. The number of cases of dengue infection in the 33rd week totaled 1097, and those were assigned as a criterion variable. The MCC results are shown in Figure 6(a). The maximum value of MCC in the 30th week was 0.645 , and the predictor was in the radius of $1000 \mathrm{~m}$; a contingency table of the confusion matrix was true-positive cases: 182, false-positive cases: 64 , false-negative cases: 43 , true-negative cases: 360 , as shown in Figure $6(\mathrm{~b})$. The maximum value of MCC in the 31 st week was 0.667 , and the predictor was in the radius of $400 \mathrm{~m}$; a contingency table of the confusion matrix was true-positive cases: 180 , false-positive cases: 54 , false-negative cases: 45 , true-negative cases: 370, as shown in Figure 6(c). The maximum value of MCC in the $32 \mathrm{nd}$ week 

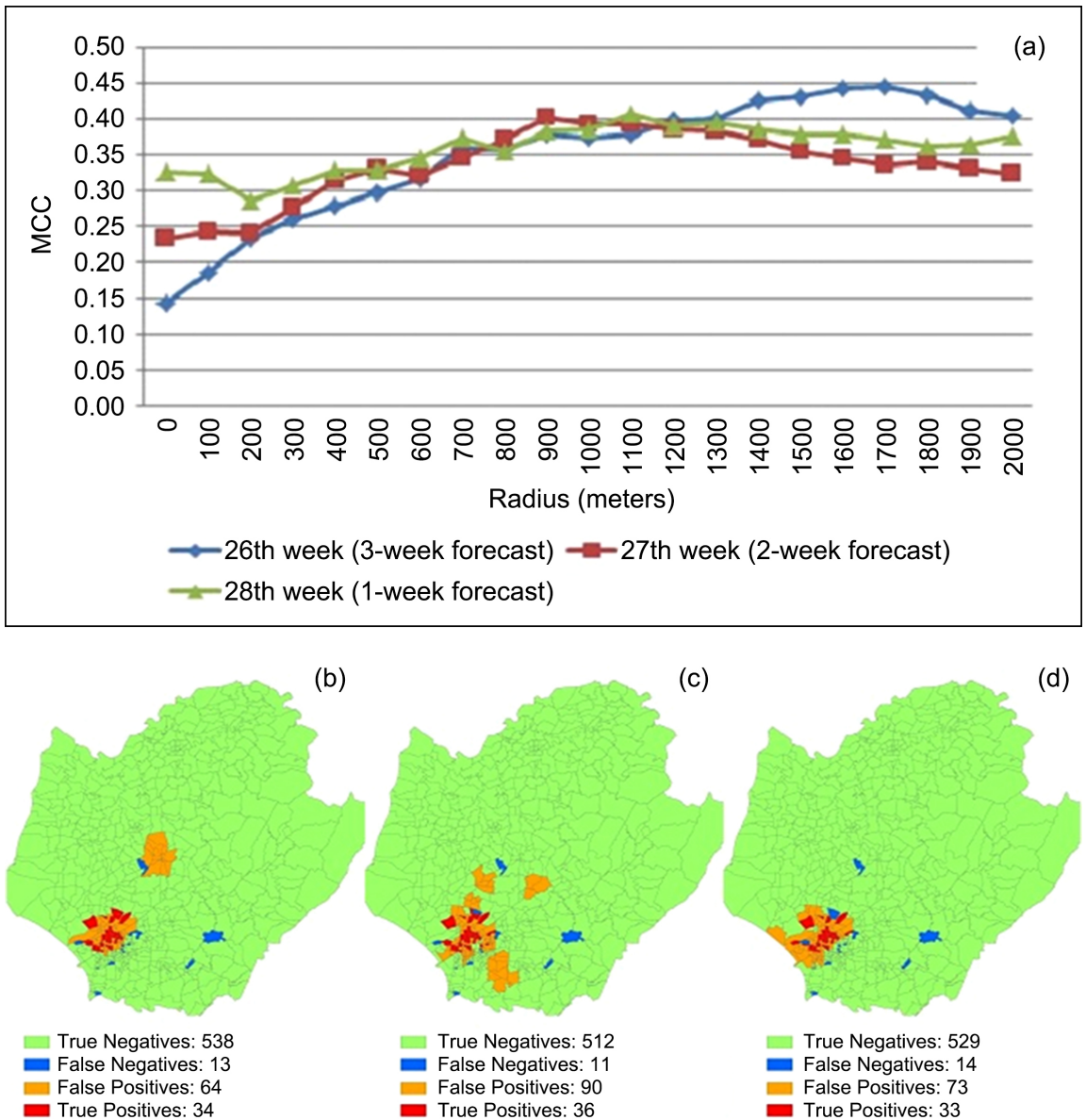

(b)

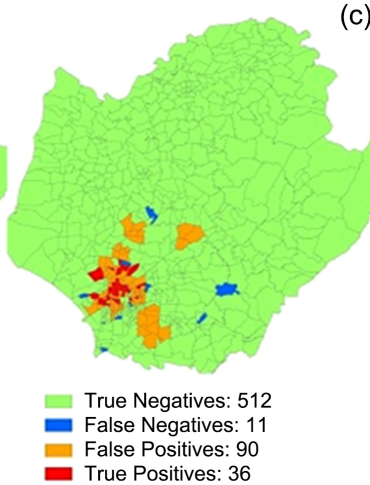

(c)

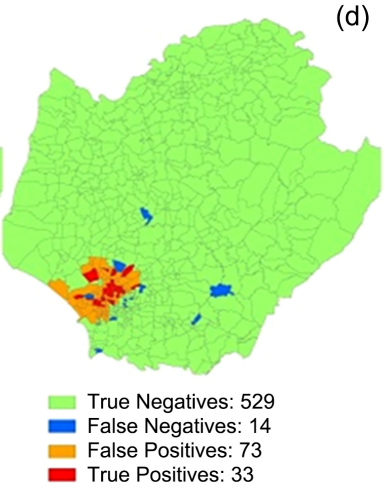

Figure 5. Model calculations using the Matthews correlation coefficient (MCC) in the lag phase. The criterion variable is the number of reported cases of dengue in the 29th week, and the predictor variable is the number of respective cases in the 26th week (3-week forecast), 27th week (2-week forecast), and 28th week (1-week forecast). (a) Outcomes predicted by the models at radii of 0 to $2000 \mathrm{~m}$ at $100-\mathrm{m}$ intervals were calculated using the MCC, including 3-week, 2-week, and 1-week forecasts. (b) Dengue risk map of the 3-week forecast within a radius of $1700 \mathrm{~m}$. (c) Dengue risk map of the 2-week forecast within a radius of $900 \mathrm{~m}$. (d) Dengue risk map of the 1-week forecast within a radius of $1100 \mathrm{~m}$.

was 0.677 , and the predictor was in the radius of $300 \mathrm{~m}$; a contingency table of the confusion matrix was true-positive cases: 185, false-positive cases: 57 , false-negative cases: 40, true-negative cases: 367, as shown in Figure 6(d). The top six outcomes of MCC values among $21 \times 3$ predictions included predictors that are radius at respective of $400,500,600$, and $700 \mathrm{~m}$ during the 31 st week and radius at respective of 200 and $300 \mathrm{~m}$ during the $32 \mathrm{nd}$ week.

In the stationary phase, the number of dengue cases predicted using the predictor variables in the 34 th week (the 3 -week forecast) totaled 1279 . That in the 35 th week (the 2-week forecast) totaled 2393, and that in the 36th week (the 1-week forecast) totaled 2871. The number of cases of dengue infection in the 37 th week totaled 3404 , and those were assigned as a criterion variable. The MCC results are shown in Figure 7(a). The maximum value of MCC in the 34th 

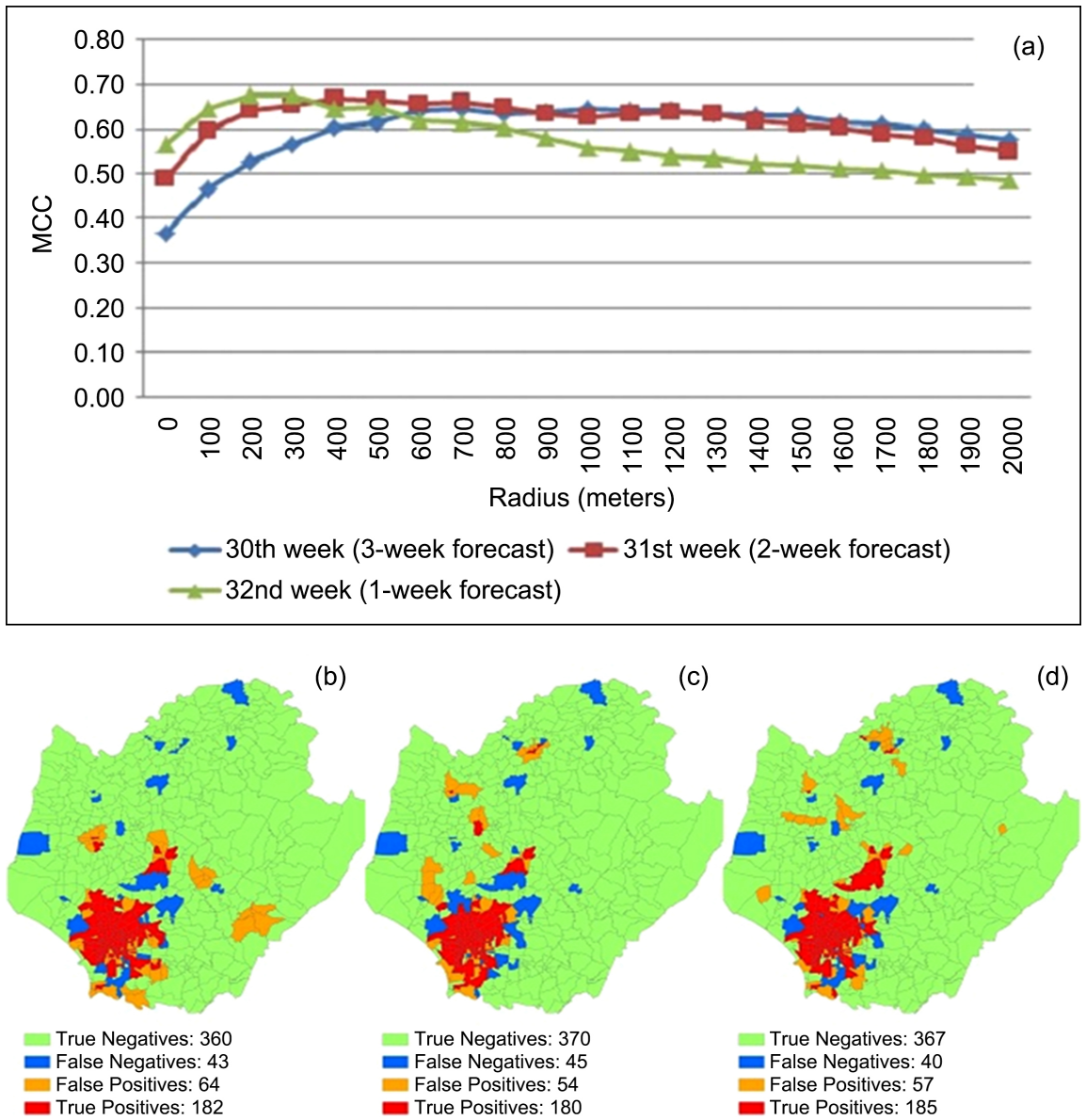

(b)

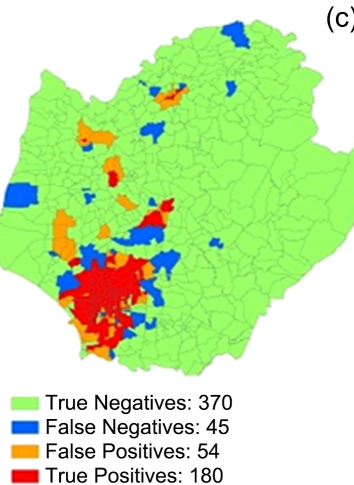

(c)

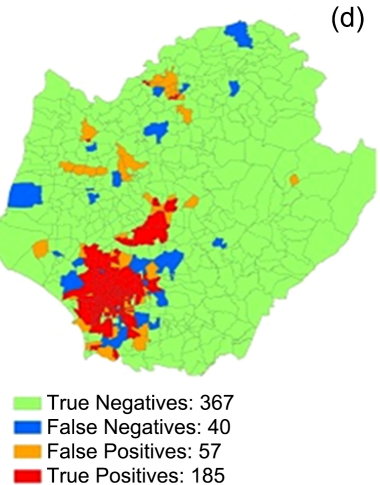

Figure 6. Model calculations using the Matthews correlation coefficient (MCC) in the exponential phase. The criterion variable was the number of reported cases of dengue in the 33rd week, and the predictor variable was the number of respective cases in the 30th week (3-week forecast), 31st week (2-week forecast), and 32nd week (1-week forecast). (a) Outcomes predicted by the models at radii of 0 to $2000 \mathrm{~m}$ at $100-\mathrm{m}$ intervals were calculated using the MCC, including 3-week, 2-week, and 1-week forecasts. (b) Dengue risk map of the 3-week forecast within a radius of $1000 \mathrm{~m}$. (c) Dengue risk map of the 2-week forecast within a radius of $400 \mathrm{~m}$. (d) Dengue risk map of the 1-week forecast within a radius of $300 \mathrm{~m}$.

week was 0.609 , and the predictor was in the radius of $100 \mathrm{~m}$; a contingency table of the confusion matrix was true-positive cases: 262, false-positive cases: 50 , false-negative cases: 78, true-negative cases: 259, as shown in Figure 7(b). The maximum value of MCC in the 35th week was 0.609 , and the predictor was in the radius of $200 \mathrm{~m}$; a contingency table of the confusion matrix was true-positive cases: 293 , false-positive cases: 80 , false-negative cases: 47 , true-negative cases: 229, as shown in Figure 7(c). The maximum value of MCC in the 36th week was 0.603 , and the predictor was in the radius of $100 \mathrm{~m}$; a contingency table of the confusion matrix was true-positive cases: 291, false-positive cases: 80 , false-negative cases: 49 , true-negative cases: 229 , as shown in Figure $7(\mathrm{~d})$. The top six outcomes of MCC values among $21 \times 3$ predictions included predictors that are radius at respective of 100 and $200 \mathrm{~m}$ during the 34 th week, radius at 

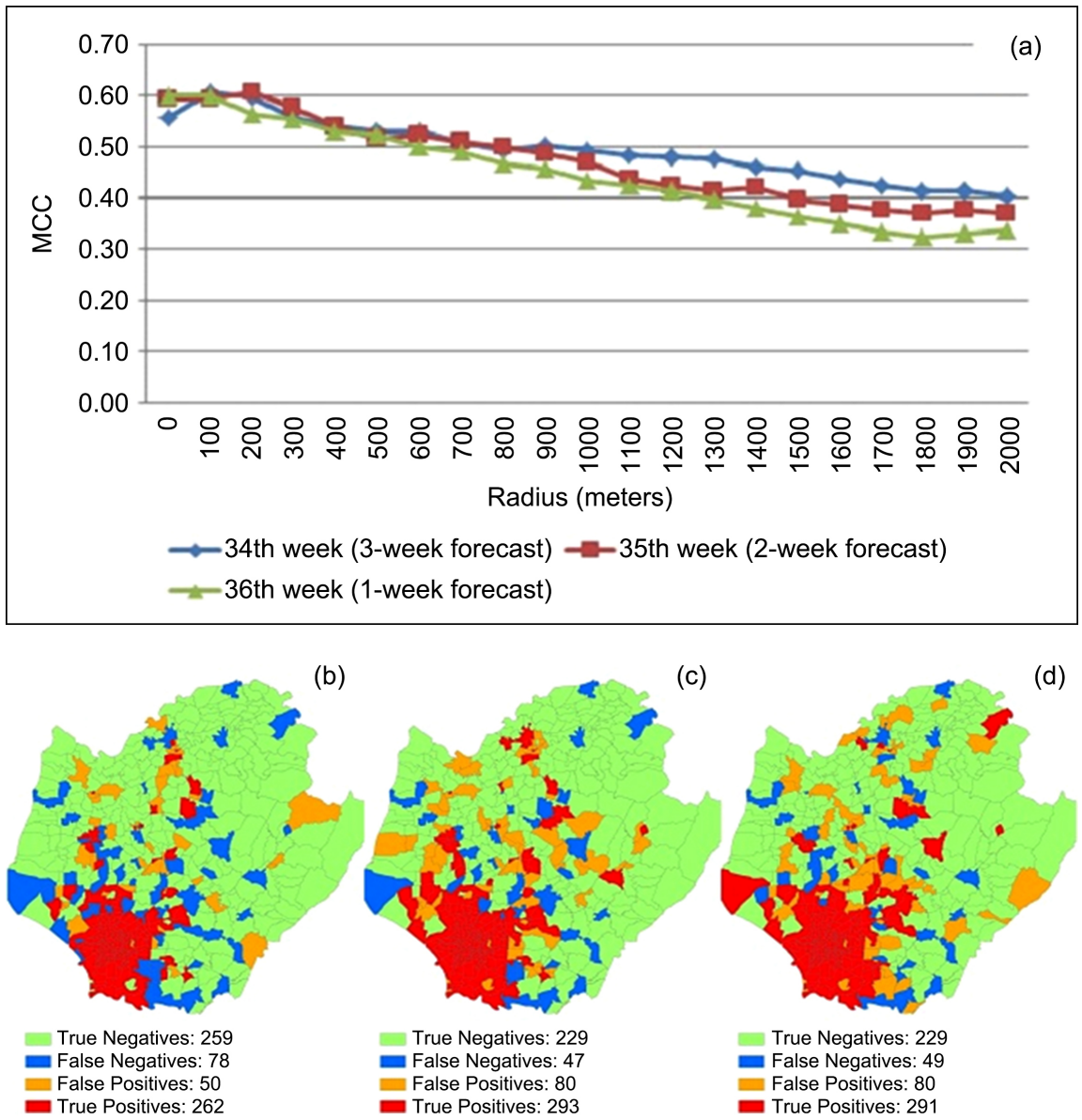

Figure 7. Model calculations using the Matthews correlation coefficient (MCC) in the stationary phase. The criterion variable was the number of reported cases of dengue in the 37 th week, and the predictor variable was the number of respective cases in the 34th week (3-week forecast), 35th week (2-week forecast), and 36th week (1-week forecast). (a) Outcomes predicted by the models at radii of 0 to $2000 \mathrm{~m}$ at $100-\mathrm{m}$ intervals were calculated using the MCC, including 3-week, 2-week, and 1-week forecasts. (b) Dengue risk map of the 3-week forecast within a radius of $100 \mathrm{~m}$. (c) Dengue risk map of the 2-week forecast within a radius of $200 \mathrm{~m}$. (d) Dengue risk map of the 1-week forecast within a radius of $100 \mathrm{~m}$.

respective of 0,100 , and $200 \mathrm{~m}$ during the 35 th week, and radius at respective of 0 and $100 \mathrm{~m}$ during the 36 th week.

In the early decline phase, the number of dengue cases of the predictor variable in the 38th week (the 3-week forecast) totaled 3023. That in the 39th week (the 2-week forecast) totaled 2230, and that in the 40th week (the 1-week forecast) totaled 1613. The number of cases of dengue infection in the 41st week totaled 1033, and those were assigned as a criterion variable. The MCC results are shown in Figure 8(a). The maximum value of MCC in the 38th week was 0.622 , and the predictor was in the radius of $0 \mathrm{~m}$; a contingency table of the confusion matrix was true-positive cases: 225 , false-positive cases: 101 , false-negative cases: 29, true-negative cases: 296, as shown in Figure 8(b). The maximum value of MCC in the 39th week was 0.610 , and the predictor was in the radius of $0 \mathrm{~m}$; 

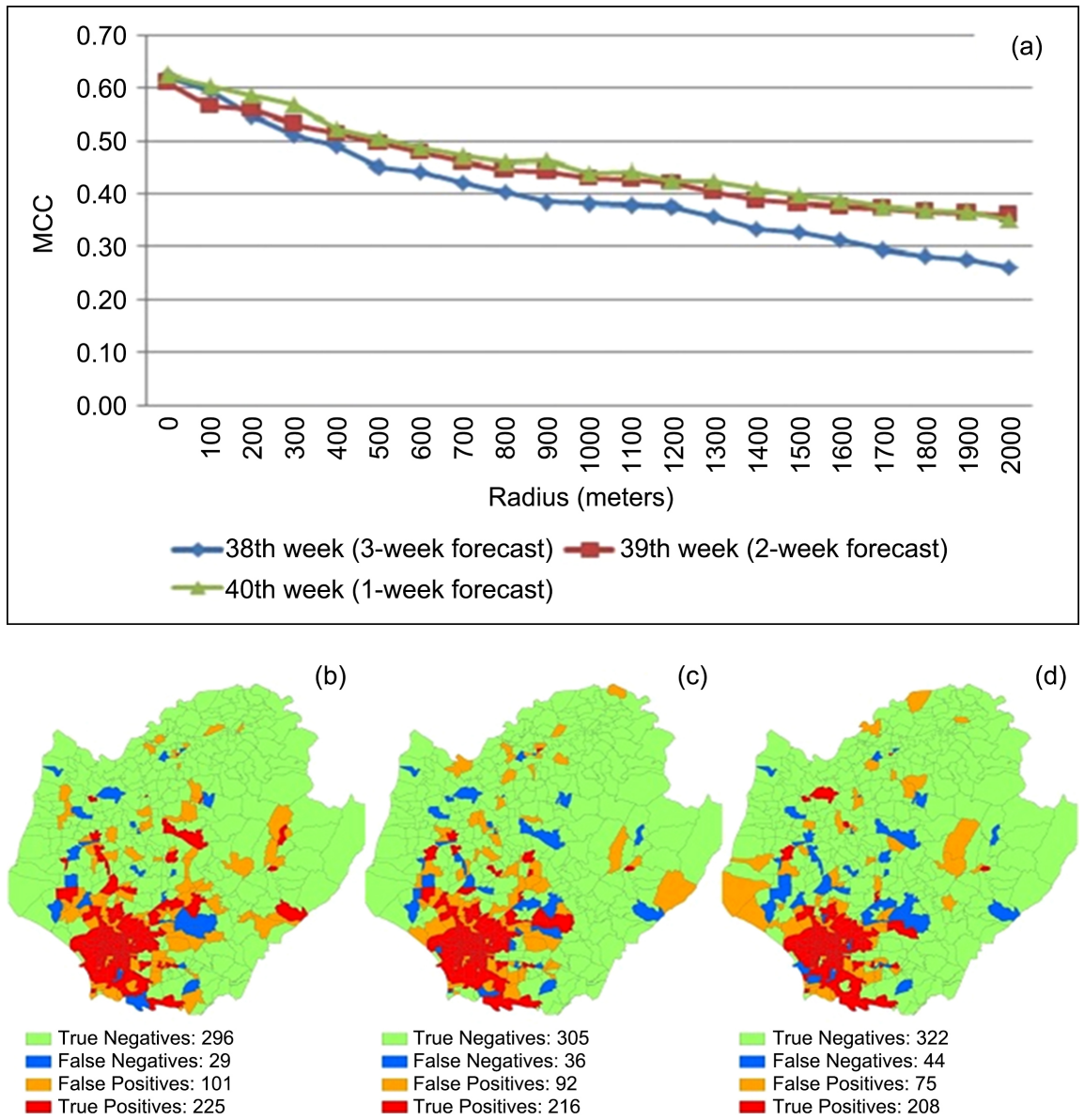

(b)

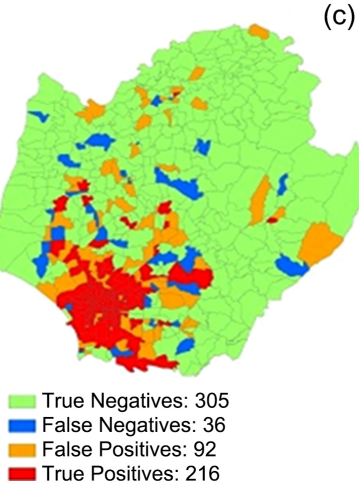

(c)

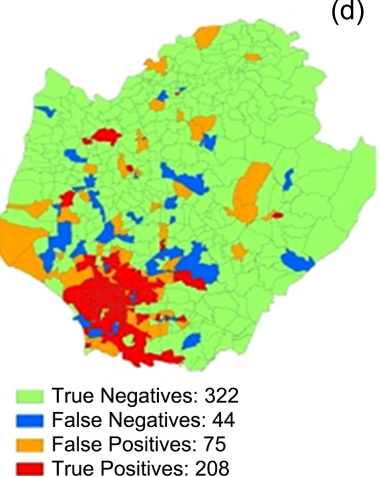

Figure 8. Model calculations using the Matthews correlation coefficient (MCC) in the early decline phase. The criterion variable was the number of reported cases of dengue in the 41 st week, and the predictor variable was the number of respective cases in the 38th week (3-week forecast), 39th week (2-week forecast), and 40th week (1-week forecast). (a)

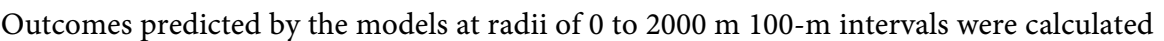
using the MCC, including 3-week, 2-week, and 1-week forecasts. (b) Dengue risk map of the 3-week forecast within a radius of $0 \mathrm{~m}$. (c) Dengue risk map of the 2-week forecast within a radius of $0 \mathrm{~m}$. (d) Dengue risk map of the 1-week forecast within a radius of $0 \mathrm{~m}$.

a contingency table of the confusion matrix was true-positive cases: 216, false-positive cases: 92, false-negative cases: 36, true-negative cases: 305, as shown in Figure 8(c). The maximum value of MCC in the 40th week was 0.626 , and the predictor was in the radius of $0 \mathrm{~m}$; a contingency table of the confusion matrix was true-positive cases: 208 , false-positive cases: 75 , false-negative cases: 44, true-negative cases: 322 , as shown in Figure $8(\mathrm{~d})$. The top six outcomes of MCC values among $21 \times 3$ predictions included predictors that are radius at respective of 0 and $100 \mathrm{~m}$ during the 38th week, radius at respective of $0 \mathrm{~m}$ during the 39th week, and radius at respective of 0,100 , and $200 \mathrm{~m}$ during the 40 th week.

In the late decline phase, the number of dengue cases predicted using the predictor variables in the $42 \mathrm{nd}$ week (the 3 -week forecast) totaled 775 . That in the 43rd week (the 2-week forecast) totaled 515, and that in the 44th week (the 
1-week forecast) totaled 322. The number of cases of dengue infection in the 45 th week totaled 196, and those were assigned as a criterion variable. The MCC results are shown in Figure 9(a). The maximum value of MCC in the 42nd week was 0.443 , and the predictor was in the radius of $0 \mathrm{~m}$; a contingency table of the confusion matrix was true-positive cases: 98, false-positive cases: 143, false-negative cases: 21, true-negative cases: 387, as shown in Figure 9(b). The maximum value of MCC in the 43rd week was 0.466 , and the predictor was in the radius of $200 \mathrm{~m}$; a contingency table of the confusion matrix was true-positive cases: 108, false-positive cases: 166, false-negative cases: 11 , true-negative cases: 364, as shown in Figure 9(c). The maximum value of MCC in the 44 th week was 0.451 , and the predictor was in the radius of $300 \mathrm{~m}$; a contingency table of the confusion matrix was true-positive cases: 106, false-positive

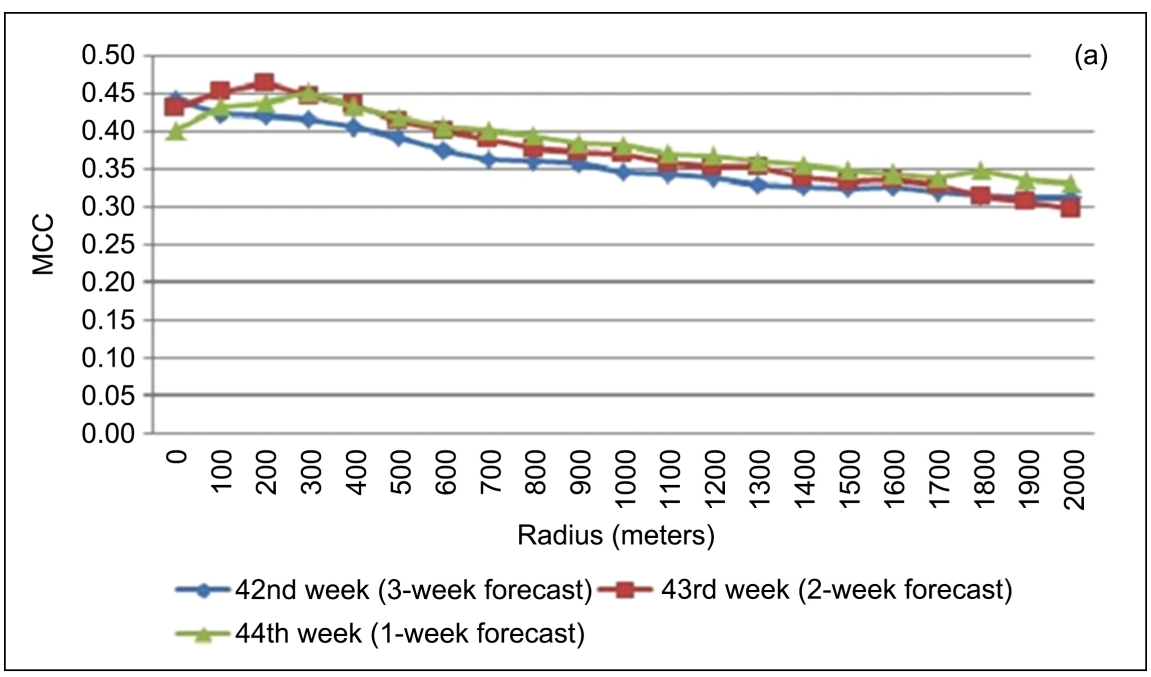

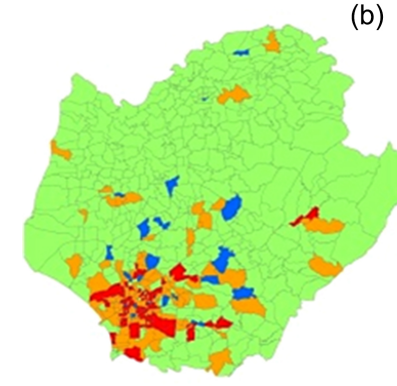

True Negatives: 387 False Negatives: 21

False Positives: 143

True Positives: 98 (c)

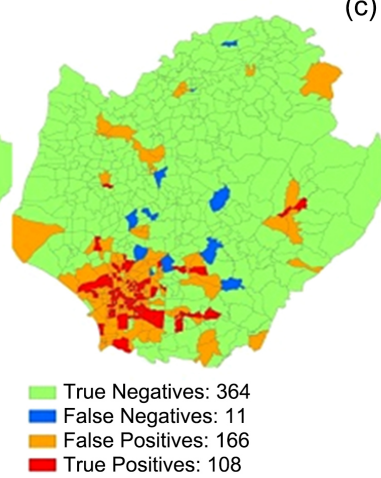

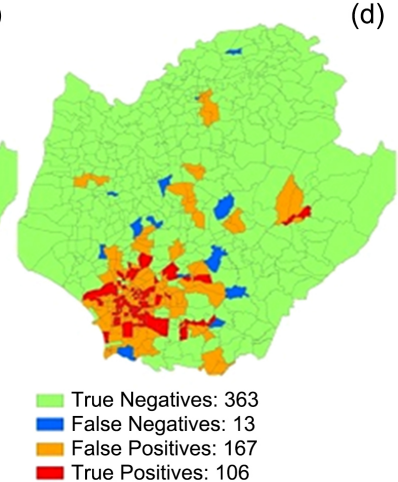

Figure 9. Model calculations using the Matthews correlation coefficient (MCC) in the late decline phase. The criterion variable was the number of reported cases of dengue in the 45 th week, and the predictor variable was the number of respective cases in the $42 \mathrm{nd}$ week (3-week forecast), 43rd week (2-week forecast), and 44th week (1-week forecast). (a) Outcomes predicted by the models at radii of 0 to $2000 \mathrm{~m}$ at $100-\mathrm{m}$ intervals were calculated using the MCC, including 3-week, 2-week, and 1-week forecasts. (b) Dengue risk map of the 3-week forecast within a radius of $0 \mathrm{~m}$. (c) Dengue risk map of the 2-week forecast within a radius of $200 \mathrm{~m}$. (d) Dengue risk map of the 1-week forecast within a radius of $300 \mathrm{~m}$. 
cases: 167, false-negative cases: 13, true-negative cases: 363, as shown in Figure 9 (d). The top six outcomes of MCC values among $21 \times 3$ predictions included predictors that are radius at respective of $0 \mathrm{~m}$ during the $42 \mathrm{nd}$ week, radius at respective of 100,200 , and $300 \mathrm{~m}$ during the $43 \mathrm{rd}$ week, and radius at respective of 200 and $300 \mathrm{~m}$ during the 44 th week.

\section{Discussion}

Both $A$. aegypti and $A$. albopictus are day-biting mosquitoes that exhibit 2 main peaks of activity: one in the early morning and the other in the late afternoon [24]. A. aegypti is endophilic and endophagic but also moves between indoor and outdoor spaces. A. albopictus also exhibits endophilic activity but is considered exophagic and is an opportunistic feeder, biting a wide range of hosts, from cold-blooded to warm-blooded animals [24]. The lower temperature limit at which $A$. aegypti has been found to cease biting is $15^{\circ} \mathrm{C}$, both in the field and experimentally in the laboratory [25]. Females are most active at $28^{\circ} \mathrm{C}$ and feed faster at temperatures between $26^{\circ} \mathrm{C}$ and $35^{\circ} \mathrm{C}$ than at temperatures between $19^{\circ} \mathrm{C}$ and $25^{\circ} \mathrm{C}$ [25]. The upper-temperature limit for blood feeding is above $36^{\circ} \mathrm{C}$, with the death point being set at $40^{\circ} \mathrm{C}$ in $A$. aegypti [25]. The length of the gonotrophic cycle decreases with increasing mean temperatures, and the shortest was observed at $26^{\circ} \mathrm{C}$ and $30^{\circ} \mathrm{C}$ [26]. In A. aegypti, the effects of a diurnal temperature range (DTR) on female adult survival have also been shown to be considerable; an increasing DTR at a mean temperature of approximately $26^{\circ} \mathrm{C}$ was reported to reduce the survival of females over an experimental period from $70 \%$ for a DTR of $0^{\circ} \mathrm{C}$ to $50 \%$ for a DTR of $10^{\circ} \mathrm{C}$ and $30 \%$ for a DTR of $20^{\circ} \mathrm{C}$ [27]. Follow-up studies have also found that a DTR of $18.6^{\circ} \mathrm{C}$ reduces female survival and reproductive output [28] [29]. A higher DTR $\left(20^{\circ} \mathrm{C}\right)$, which can be seen in temperate climates in spring and autumn, hurts the vector competence for dengue and the survival of $A$. aegypti compared with a low DTR $\left(10^{\circ} \mathrm{C}\right)$, such as the temperature ranges typically experienced in summer [27].

Both $A$. albopictus and $A$. aegypti are susceptible to dengue virus (DENV). However, multiple blood feedings in a single gonotrophic cycle are more frequent in $A$. aegypti [30] [31] [32]. Such behavioral differences may provide fewer opportunities for $A$. albopictus to make contact with humans infected by DENV. Thus, A. albopictus has a lower probability of transmitting the virus through the intake of blood [33]. One study on field-caught mosquitoes in Singapore showed that $6.9 \%$ of $A$. aegypti but only $2.9 \%$ of $A$. albopictus were positive for DENV [34]. Another study in Singapore showed that infected A. aegypti were detected as early as 6 weeks before the start of a dengue outbreak, whereas infected $A$. albopictus did not appear until the number of cases was increasing [35]. Furthermore, an investigation conducted in southern Taiwan revealed that DENV was detected at low levels only from $0.2 \%$ positive signs among field-caught $A$. aegypti but not $A$. albopictus [36]. Notably, large outbreaks such as those in 2006 and 2007 occurred 1 year after the detection of virus-infected $A$. 
aegypti [36]. These results indicate the possibility that $A$. aegypti can efficiently establish a preliminary dengue case cluster.

DENV is transmitted to humans through the bites of infected female mosquitoes, primarily the $A$. aegypti mosquito. After a mosquito has fed from a DENV-infected person, the virus replicates in the mosquito's midgut, disseminates to its salivary glands, and emerges in its saliva; consequently, the virus can be transmitted when the mosquito bites again [37]. The minimum time between ingestion of virus-infected blood and transmission to a new host is termed the extrinsic incubation period (EIP). The EIP is approximately 8 to 12 days when the ambient temperature is between $25^{\circ} \mathrm{C}$ and $28^{\circ} \mathrm{C}$ [38] [39]. Variations in the extrinsic incubation period are not influenced solely by ambient temperature; several other factors, such as the magnitude of daily temperature fluctuations [27] [40], virus genotype [41], and initial viral concentration [42], can also alter the time it takes for a mosquito to transmit the virus. Once infectious, the mosquito is capable of transmitting a virus for the rest of its life [43]. $\mathrm{Hu}$ man-to-mosquito transmission can occur up to 2 days before the infected person exhibits symptoms of DF, dengue hemorrhagic fever, or dengue shock syndrome [44] as well as up to 2 days after the fever has resolved [45]. Risk of mosquito infection is positively associated with high viremia and high fever in the patient, and high levels of DENV-specific antibodies are associated with a decreased risk of mosquito infection [45]. Most people are viremic for approximately 4 to 5 days, but viremia can last as long as 12 days [46].

Some incentives may affect the flight distance of mosquitoes, such as a female mosquito's search for food (i.e., dew, nectar, or blood), mating partner, and spawning opportunities and male mosquito's search for mating opportunities and food, mainly dew and nectar [47] [48]. Moreover, these incentives could cause their flight distance to expand because female Aedes mosquitoes have a habit of dispersed spawning [49]. As reported in mark-release-recapture experiments, the majority of recaptured mosquitoes (92\% - 99\%) were recaptured less than $100 \mathrm{~m}$ from their release site, and most mosquitoes were recaptured in the same house as the release location or in an adjacent house. The flight range and dispersal distance of $A$. aegypti were significantly different from the layout of the village and the distance between houses, regardless of mosquito age, sex (male versus female), release location (indoors versus outdoors), and season (high versus low dengue transmission season) [50]. However, the dispersal distance of $A$. albopictus was greater than that of $A$. aegypti; $11.1 \%$ of $A$. albopictus mosquitoes were recaptured farther than $100 \mathrm{~m}$ from their release point [51]. In another study of flight range for female $A$. aegypti and $A$. albopictus, a search for oviposition sites was implemented using rubidium-marked egg experiments. In 6 days, rubidium-marked eggs of both species were detected up to $800 \mathrm{~m}$ from the release point. Eggs of $A$. albopictus were more numerous and more heterogeneously distributed in the study area than those of $A$. aegypti. Eggs positively marked for rubidium were found at all of the studied borders, which strongly 
suggests that their flight ranges are capable of surpassing the studied limit at 800 $\mathrm{m}$ [52]. The flight ranges and dispersal of gravid females were influenced by the availability of oviposition sites [53]. However, the egg-laying site may represent the start of the next reproductive cycle for these female mosquitoes.

\section{Conclusion}

Prediction of new-onset DF in an urban village based on the distance from the household location of a previously reported case of dengue is simple and effective. According to the outcomes of 5 studied phases that were based on a large wave of an indigenous dengue epidemic, the distance of the optimal predictor varies by phase. In the lag phase, the optimal predictor is within $1700 \mathrm{~m}$ in the 3-week forecast. In the exponential phase, the optimal predictor is within $300 \mathrm{~m}$ in the 1-week forecast. In the stationary phase, the optimal predictor is within $100 \mathrm{~m}$ in the 3-week forecast and within $200 \mathrm{~m}$ in the 2-week forecast. In the early decline phase, the optimal predictor is $0 \mathrm{~m}$ in the 1-week forecast. In the late decline phase, the optimal predictor is within $200 \mathrm{~m}$ in the 2-week forecast. In summary, optimal model predictions during the dengue explosion in Tainan City in 2015 were made in the exponential phase, when the number of dengue infections was dramatically increasing.

\section{Conflicts of Interest}

The author declares no conflicts of interest regarding the publication of this paper.

\section{References}

[1] Bhatt, S., Gething, P.W., Brady, O.J., Messina, J.P., Farlow, A.W., Moyes, C.L., Drake, J.M., Brownstein, J.S., Hoen, A.G., Sankoh, O., Myers, M.F., George, D.B., Jaenisch, T., Wint, G.R., Simmons, C.P., Scott, T.W., Farrar, J.J. and Hay, S.I. (2013) The Global Distribution and Burden of Dengue. Nature, 496, 504. https://doi.org/10.1038/nature12060

[2] Brady, O.J., Gething, P.W., Bhatt, S., Messina, J.P., Brownstein, J.S., Hoen, A.G., Moyes, C.L., Farlow, A.W., Scott, T.W. and Hay, S.I. (2012) Refining the Global Spatial Limits of Dengue Virus Transmission by Evidence-Based Consensus. PLOS Neglected Tropical Diseases, 6, e1760. https://doi.org/10.1371/journal.pntd.0001760

[3] Lambrechts, L., Scott, T.W. and Gubler, D.J. (2010) Consequences of the Expanding Global Distribution of Aedes albopictus for Dengue Virus Transmission. PLOS Neglected Tropical Diseases, 4, e646.

https://doi.org/10.1371/journal.pntd.0000646.t002

[4] McKnight, T.L. and Hess, D. (2000) Physical Geography: A Landscape Appreciation. Pearson Prentice Hall, Upper Saddle River.

[5] Lin, T.H. (1994) Surveillance and Control of Aedes aegypti in Epidemic Areas of Taiwan. The Kaohsiung Journal of Medical Sciences, 10, S88-S93.

[6] Lin, C., Wang, C.Y. and Teng, H.J. (2014) The Study of Dengue Vector Distribution in Taiwan from 2009 to 2011. Taiwan Epidemiology Bulletin, 30, 304-310. (In Chinese) 
[7] Lin, C.C., Huang, Y.H., Shu, P.Y., Wu, H.S., Lin, Y.S., Yeh, T.M., Liu, H.S., Liu, C.C. and Lei, H.Y. (2010) Characteristic of Dengue Disease in Taiwan: 2002-2007. The American Journal of Tropical Medicine and Hygiene, 82, 731-739. https://doi.org/10.4269/ajtmh.2010.09-0549

[8] Shu, P.Y., Su, C.L., Liao, T.L., Yang, C.F., Chang, S.F., Lin, C.C., Chang, M.C., Hu, H.C. and Huang, J.H. (2009) Molecular Characterization of Dengue Viruses Imported into Taiwan during 2003-2007: Geographic Distribution and Genotype Shift. The American Journal of Tropical Medicine and Hygiene, 80, 1039-1046. https://doi.org/10.4269/ajtmh.2009.80.1039

[9] Huang, J.H., Su, C.L., Yang, C.F., Liao, T.L., Hsu, T.C., Chang, S.F., Lin, C.C. and Shu, P.Y. (2012) Molecular Characterization and Phylogenetic Analysis of Dengue Viruses Imported into Taiwan during 2008-2010. The American Journal of Tropical Medicine and Hygiene, 87, 349-358. https://doi.org/10.4269/ajtmh.2012.11-0666

[10] van Panhuis, W.G., Choisy, M., Xiong, X., Chok, N.S., Akarasewi, P., Iamsirithaworn, S., Lam, S.K., Chong, C.K., Lam, F.C., Phommasak, B., Vongphrachanh, P., Bouaphanh, K., Rekol, H., Hien, N.T., Thai, P.Q., Duong, T.N., Chuang, J.H., Liu, Y.L., Ng, L.C., Shi, Y., Tayag, E.A., Roque, V.G. Jr., Lee Suy, L.L., Jarman, R.G., Gibbons, R.V., Velasco, J.M., Yoon, I.K., Burke, D.S. and Cummings, D.A. (2015) Region-Wide Synchrony and Traveling Waves of Dengue across Eight Countries in Southeast Asia. Proceedings of the National Academy of Sciences of the United States of America, 112, 13069-13074. https://doi.org/10.1073/pnas.1501375112

[11] Chen, K.T., Chau, M.Y. and Malison, M. (1987) Preliminary Investigation Report of an Outbreak of Dengue Fever in Kaohsiung and Pingtung, Southern Taiwan. Epidemiological Bulletin, 93-95.

[12] Taiwan's Centers for Disease Control (2020) Taiwan National Infectious Disease Statistics System.

http://nidss.cdc.gov.tw/en/?treeid=00ED75D6C887BB27\&nowtreeid=D39475C2DB 7CD87B.\%202020

[13] Yu, H.L., Angulo, J.M., Cheng, M.H., Wu, J. and Christakos, G. (2014) An Online Spatiotemporal Prediction Model for Dengue Fever Epidemic in Kaohsiung (Taiwan). Biometrical Journal, 56, 428-440. https://doi.org/10.1002/bimj.201200270

[14] Chen, C.C. and Chang, H.C. (2013) Predicting Dengue Outbreaks Using Approximate Entropy Algorithm and Pattern Recognition. Journal of Infection, 67, 65-71. https://doi.org/10.1016/j.jinf.2013.03.012

[15] Chang, F.S., Tseng, Y.T., Hsu, P.S., Chen, C.D., Lian, I.B. and Chao, D.Y. (2015) Re-Assess Vector Indices Threshold as an Early Warning Tool for Predicting Dengue Epidemic in a Dengue Non-Endemic Country. PLOS Neglected Tropical Diseases, 9, e0004043. https://doi.org/10.1371/journal.pntd.0004043

[16] Yuan, H.Y., Wen, T.H., Kung, Y.H., Tsou, H.H., Chen, C.H., Chen, L.W. and Lin, P.S. (2019) Prediction of Annual Dengue Incidence by Hydro-Climatic Extremes for Southern Taiwan. International Journal of Biometeorology, 63, 259-268. https://doi.org/10.1007/s00484-018-01659-w

[17] Chan, T.C., Hu, T.H. and Hwang, J.S. (2015) Daily Forecast of Dengue Fever Incidents for Urban Villages in a City. International Journal of Health Geographics, 14, 9. https://doi.org/10.1186/1476-072X-14-9

[18] Ministry of the Interior, Republic of China (Taiwan) (2020) Department of Household Registration. https://www.ris.gov.tw/app/portal/346

[19] Taiwan's Centers for Disease Control (2020) Dengue Daily Confirmed Cases since 1998. https://data.cdc.gov.tw/dataset 
[20] Taiwan's Centers for Disease Control (2020) Taiwan National Infectious Disease Statistics System. https://nidss.cdc.gov.tw/ch

[21] Matthews, B.W. (1975) Comparison of the Predicted and Observed Secondary Structure of T4 Phage Lysozyme. Biochimica et Biophysica Acta (BBA) Protein Structure, 405, 442-451. https://doi.org/10.1016/0005-2795(75)90109-9

[22] Chicco, D. and Jurman, G. (2020) The Advantages of the Matthews Correlation Coefficient (MCC) over F1 Score and Accuracy in Binary Classification Evaluation. BMC Genomics, 21, 6. https://doi.org/10.1186/s12864-019-6413-7

[23] Boughorbel, S., Jarray, F. and El-Anbari, M. (2017) Optimal Classifier for Imbalanced Data Using Matthews Correlation Coefficient Metric. PLOS ONE, 12, e0177678. https://doi.org/10.1371/journal.pone.0177678

[24] Delatte, H., Desvars, A., Bouétard, A., Bord, S., Gimonneau, G., Vourc'h, G. and Fontenille, D. (2010) Blood-Feeding Behavior of Aedes albopictus, a Vector of Chikungunya on La Réunion. Vector-Borne and Zoonotic Diseases, 10, 249-258. https://doi.org/10.1089/vbz.2009.0026

[25] Reinhold, J.M., Lazzari, C.R. and Lahondère, C. (2018) Effects of the Environmental Temperature on Aedes aegypti and Aedes albopictus Mosquitoes: A Review. Insects, 9, pii: E158. https://doi.org/10.3390/insects9040158

[26] Carrington, L.B., Armijos, M.V., Lambrechts, L., Barker, C.M. and Scott, T.W. (2013) Effects of Fluctuating Daily Temperatures at Critical Thermal Extremes on Aedes aegypti Life-History Traits. PLoS ONE, 8, e58824.

https://doi.org/10.1371/journal.pone.0058824

[27] Lambrechts, L., Paaijmans, K.P., Fansiri, T., Carrington, L.B., Kramer, L.D., Thomas, M.B. and Scott, T.W. (2011) Impact of Daily Temperature Fluctuations on Dengue Virus Transmission by Aedes aegypti. Proceedings of the National Academy of Sciences of the United States of America, 108, 7460-7465. https://doi.org/10.1073/pnas.1101377108

[28] Carrington, L.B., Seifert, S.N., Willits, N.H., Lambrechts, L. and Scott, T.W. (2013) Large Diurnal Temperature Fluctuations Negatively Influence Aedes aegypti (Diptera:Culicidae) Life-History Traits. Journal of Medical Entomology, 50, 43-51. https://doi.org/10.1603/ME11242

[29] Carrington, L.B., Seifert, S.N., Armijos, M.V., Lambrechts, L. and Scott, T.W. (2013) Reduction of Aedes aegypti Vector Competence for Dengue Virus under Large Temperature Fluctuations. The American Journal of Tropical Medicine and $\mathrm{Hy}$ giene, 88, 689-697. https://doi.org/10.4269/ajtmh.12-0488

[30] Scott, T.W., Clark, G.G., Lorenz, L.H., Amerasinghe, P.H., Reiter, P. and Edman, J.D. (1993) Detection of Multiple Blood Feeding in Aedes aegypti (Diptera: Culicidae) during a Single Gonotrophic Cycle Using a Histologic Technique. Journal of Medical Entomology, 30, 94-99. https://doi.org/10.1093/jmedent/30.1.94

[31] Canyon, D.V., Hii, J.L. and Muller, R. (1999) The Frequency of Host Biting and Its Effect on Oviposition and Survival in Aedes aegypti (Diptera: Culicida). Journal of Medical Entomology, 36, 301-308. https://doi.org/10.1093/jmedent/36.3.301

[32] Ponlawat, A. and Harrington, L.C. (2005) Blood Feeding Patterns of Aedes aegypti and Aedes albopictus in Thailand. Journal of Medical Entomology, 42, 844-849. https://doi.org/10.1093/jmedent/42.5.844

[33] Chen, W.J., Wei, H.L., Hsu, E.L. and Chen, E.R. (1993) Vector Competence of Aedes albopictus and Ae. aegypti (Diptera: Culicidae) to Dengue 1 Virus in Taiwan: Development of the Virus in the Orally and Parenterally Infected Mosquitoes. Journal of Medical Entomology, 30, 524-530. 
https://doi.org/10.1093/imedent/30.3.524

[34] Chung, Y.K. and Pang, F.Y. (2002) Dengue Virus Infection Rate in Field Populations of Female Aedes aegypti and Aedes albopictus in Singapore. Tropical Medicine \& International Health, 7, 322-330. https://doi.org/10.1046/j.1365-3156.2002.00873.x

[35] Chow, V.T., Chan, Y.C., Yong, R., Lee, K.M., Lim, L.K., Chung, Y.K., Lam-Phua, S.G. and Tan, B.T. (1998) Monitoring of Dengue Viruses in Field-Caught Aedes aegypti and Aedes albopictus Mosquitoes by a Type-Specific Polymerase Chain Reaction and Cycle Sequencing. The American Journal of Tropical Medicine and Hygiene, 58, 578-586. https://doi.org/10.4269/ajtmh.1998.58.578

[36] Chen, C.F., Shu, P.Y., Teng, H.J., Su, C.L., Wu, J.W., Wang, J.H., Lin, T.H., Huang, J.H. and Wu, H.S. (2010) Screening of Dengue Virus in Field-Caught Aedes aegypti and Aedes albopictus (Diptera: Culicidae) by One-Step SYBR Green-Based Reverse Transcriptase-Polymerase Chain Reaction Assay during 2004-2007 in Southern Taiwan. Vector-Borne and Zoonotic Diseases, 10, 1017-1025. https://doi.org/10.1089/vbz.2008.0069

[37] Hardy, J.L., Houk, E.J., Kramer, L.D. and Reeves, W.C. (1983) Intrinsic Factors Affecting Vector Competence of Mosquitoes for Arboviruses. Annual Review of Entomology, 28, 229-262. https://doi.org/10.1146/annurev.en.28.010183.001305

[38] Watts, D.M., Burke, D.S., Harrison, B.A., Whitmire, R.E. and Nisalak, A. (1987) Effect of Temperature on the Vector Efficiency of Aedes aegypti for Dengue 2 Virus. The American Journal of Tropical Medicine and Hygiene, 36, 143-152. https://doi.org/10.4269/ajtmh.1987.36.143

[39] Tjaden, N.B., Thomas, S.M., Fischer, D. and Beierkuhnlein, C. (2013) Extrinsic Incubation Period of Dengue: Knowledge, Backlog, and Applications of Temperature Dependence. PLOS Neglected Tropical Diseases, 7, e2207. https://doi.org/10.1371/journal.pntd.0002207

[40] Carrington, L.B., Armijos, M.V., Lambrechts, L. and Scott, T.W. (2013) Fluctuations at a Low Mean Temperature Accelerate Dengue Virus Transmission by Aedes aegypti. PLOS Neglected Tropical Diseases, 7, e2190. https://doi.org/10.1371/journal.pntd.0002190

[41] Anderson, J.R. and Rico-Hesse, R. (2006) Aedes aegyptivectorial Capacity Is Determined by the Infecting Genotype of Dengue Virus. The American Journal of Tropical Medicine and Hygiene, 75, 886-892. https://doi.org/10.4269/ajtmh.2006.75.886

[42] Ye, Y.H., Carrasco, A.M., Frentiu, F.D., Chenoweth, S.F., Beebe, N.W., van den Hurk, A.F., Simmons, C.P., O’Neill, S.L. and McGraw, E.A. (2015) Wolbachia Reduces the Transmission Potential of Dengue-Infected Aedes aegypti. PLOS Neglected Tropical Diseases, 9, e0003894. https://doi.org/10.1371/journal.pntd.0003894

[43] Rückert, C. and Ebel, G.D. (2018) How Do Virus-Mosquito Interactions Lead to Viral Emergence? Trends in Parasitology, 34, 310-321. https://doi.org/10.1016/j.pt.2017.12.004

[44] Duong, V., Lambrechts, L., Paul R.E., Ly, S., Lay, R.S., Long, K.C., Huy, R., Tarantola, A., Scott, T.W., Sakuntabhai, A. and Buchy, P. (2015) Asymptomatic Humans Transmit Dengue Virus to Mosquitoes. Proceedings of the National Academy of Sciences of the United States of America, 112, 14688-14693. https://doi.org/10.1073/pnas.1508114112

[45] Nguyet, M.N., Duong, T.H., Trung, V.T., Nguyen, T.H., Tran, C.N., Long, V.T., Dui le, T., Nguyen, H.L., Farrar, J.J., Holmes, E.C., Rabaa, M.A., Bryant, J.E., Nguyen, 
T.T., Nguyen, H.T., Nguyen, L.T., Pham, M.P., Nguyen, H.T., Luong, T.T., Wills, B., Nguyen, C.V., Wolbers, M. and Simmons, C.P. (2013) Host and Viral Features of Human Dengue Cases Shape the Population of Infected and Infectious Aedes aegypti Mosquitoes. Proceedings of the National Academy of Sciences of the United States of America, 110, 9072-9077. https://doi.org/10.1073/pnas.1303395110

[46] Gubler, D.J., Suharyono, W., Tan, R., Abidin, M. and Sie, A. (1981) Viraemia in Patients with Naturally Acquired Dengue Infection. Bulletin of the World Health Organization, 59, 623-630.

[47] Estrada-Franco, J.G. and Craig, G.B.J. (1995) Biology, Disease Relationships, and Control of Aedes albopictus. Pan American Health Organization, Pan American Sanitary Bureau, Regional Office of the World Health Organization, 1-49.

[48] Honório, N.A., Silva Wda, C., Leite, P.J., Gonçalves, J.M., Lounibos, L.P. and Lourenço-de-Oliveira, R. (2003) Dispersal of Aedes aegypti and Aedes albopictus (Diptera: Culicidae) in an Urban Endemic Dengue Area in the State of Rio de Janeiro, Brazil. Memórias do Instituto Oswaldo Cruz, 98, 191-198. https://doi.org/10.1590/S0074-02762003000200005

[49] Colton, Y.M., Chadee, D.D. and Severson, D.W. (2003) Natural Skip Oviposition of the Mosquito Aedes aegypti Indicated by Codominant Genetic Markers. Medical and Veterinary Entomology, 17, 195-204. https://doi.org/10.1046/j.1365-2915.2003.00424.x

[50] Harrington, L.C., Scott, T.W., Lerdthusnee, K., Coleman, R.C., Costero, A., Clark, G.G., Jones, J.J., Kitthawee, S., Kittayapong, P., Sithiprasasna, R. and Edman, J.D. (2005) Dispersal of the Dengue Vector Aedes aegypti within and between Rural Communities. The American Journal of Tropical Medicine and Hygiene, 72, 209-220. https://doi.org/10.4269/ajtmh.2005.72.209

[51] Niebylski, M.L. and Craig, G.B. Jr. (1994) Dispersal and Survival of Aedes albopictus at a Scrap Tire Yard in Missouri. Journal of the American Mosquito Control Association, 10, 339-343.

[52] Reiter, P., Amador, M.A., Anderson, R.A. and Clark, G.G. (1995) Short Report: Dispersal of Aedes aegypti in an Urban Area after Blood Feeding as Demonstrated by Rubidium-Marked Eggs. The American Journal of Tropical Medicine and Hygiene, 52, 177-179. https://doi.org/10.4269/ajtmh.1995.52.177

[53] Edman, J.D., Scott, T.W., Costero, A., Morrison, A.C., Harrington, L.C. and Clark, G.G. (1998) Aedes aegypti (Diptera: Culicidae) Movement Influenced by Availability of Oviposition Sites. Journal of Medical Entomology, 35, 578-583.

https://doi.org/10.1093/jmedent/35.4.578 